\title{
Carnets
}

Revue électronique d'études françaises de l'APEF

Première Série - 2 Numéro Spécial 10-11 | 2011

D'un Nobel l'autre

\section{Figurações do feminino em Printemps et autres saisons de J.-M. G. Le Clézio}

Ana Alexandra Seabra De Carvalho

\section{OpenEdition}

1 Journals

\section{Edição electrónica}

URL: http://journals.openedition.org/carnets/5553

DOI: 10.4000/carnets.5553

ISSN: 1646-7698

\section{Editora}

APEF

Edição impressa

Data de publição: 1 Janeiro 2011

Paginação: 101-121

\section{Refêrencia eletrónica}

Ana Alexandra Seabra De Carvalho, «Figurações do feminino em Printemps et autres saisons de J.-M. G. Le Clézio », Carnets [Online], Première Série - 2 Numéro Spécial 10-11 | 2011, posto online no dia 16 junho 2018, consultado o 02 maio 2019. URL : http://journals.openedition.org/carnets/5553 ; DOI : $10.4000 /$ carnets.5553

\section{(c) (1) (8)}

Carnets est mis à disposition selon les termes de la licence Creative Commons - Atribution - Pas d'utilisation commerciale 4.0 International. 


\title{
FIGURAÇÕES DO FEMININO EM PRINTEMPS ET AUTRES SAISONS DE J.-M. G. LE CLÉZIO
}

\author{
Ana Alexandra Seabra de Carvalho \\ FCHS Universidade do Algarve \\ CLEPUL \\ aacarva@ualg.pt
}

\begin{abstract}
Resumo
Tendo-se estreado literariamente em 1963 com Le Procès-Verbal, um romance que problematiza o código romanesco em sintonia com as propostas teóricas do nouveau roman herdadas da década anterior, e que the valeu o prémio Renaudot, Le Clézio mostrar-se-á doravante não apenas um escritor prolífico, mas, acima de tudo, constantemente em busca de novos objectos de observação e de novas formas de escrita. Servindo-se da escrita como meio de autoconhecimento e de tentativa de compreensão dos outros e do universo, viajará de uma estética próxima do nouveau roman para uma outra que, a pouco e pouco, recupera o romanesco, o maravilhoso, o mitológico, o histórico, etc., transfigurando, contudo, os códigos narrativos do passado. A composição de Printemps et autres saisons revela cinco figuras femininas, que podem ser vistas como símbolos de transformação, de errância, de renascimento para o amor e a vida.
\end{abstract}

\begin{abstract}
Le Clézio published his first literary work, Le Procès-Verbal, in 1963. This novel questions narrative code according to the theoretical proposals of the Nouveau Roman, inherited from the precedent decade, and meant him the Renaudot Prize. From this moment on, Le Clézio reveals himself not only as a prolific writer, but above all as a researcher for new objects of study and for new forms of writing. In fact, by using writing both as a mean to self-consciousness and as an attempt to understand others and the universe, he wanders from an aesthetic close to the Nouveau Roman to another that, little by little, recovers, among other aspects, the wonder of fabulous, imaginary, mythological or historical fiction. However, the novelist continues to transform the narrative codes from the past. Printemps et autres saisons's composition reveals five female characters, which can be seen as symbols of transformation, wandering and rebirth for love and for life.
\end{abstract}

Palavras-chave: Le Clézio, feminino, errância, busca interior, transformação

Keywords: Le Clézio, femininity, wandering, inner quest, transformation 
Tous les livres de Le Clézio sont en effet des paraboles de la solitude et de l'errance, inéluctables fatalités de la condition humaine; paraboles aussi de l'ambiguïté de la vie et de ses langages, ambiguïté qui constitue l'inéluctable fatalité de l'expression humaine. (Lemaître, 1994: 495)

A obra literária do escritor galardoado, entre outros, com o Prémio Nobel de Literatura de 2008, Jean-Marie Gustave Le Clézio", será, quanto a mim, sem margem para dúvidas, um dos melhores exemplos do espírito que anima a temática proposta para o Colóquio APEF 2009: reconhecimento, percursos e mutações nas literaturas de língua francesa.

Com efeito, se a consagração, pela Academia sueca, em 1985, da obra de Claude Simon $^{2}$ pode representar, em certa medida, igualmente o reconhecimento tardio da originalidade do movimento do nouveau roman, cuja "desconfiança", contestação e subversão face ao código narrativo realista-naturalista marca, contudo, uma importante época da literatura francesa, mais de duas décadas separam os dois últimos prémios Nobel de Literatura atribuídos a escritores franceses.

Uma das principais razões geralmente apontadas para a perda de influência cultural por parte de França prende-se, como todos bem sabemos, com a galopante hegemonia, a todos os níveis, da cultura anglófona, liderada pelos EUA, precisamente desde os alvores dos anos 80 do século passado. Nomeadamente no campo do literário, os gostos do novo público leitor alteram-se de acordo com as novas tendências, com a influência da cultura de massas, mas também com uma certa saturação dos jogos, por vezes demasiado solipsistas, da escrita ligada ao nouveau roman, esse "laboratório" da narrativa e da escrita, lugar mais de pesquisa formal do que de efabulação.

Como sintetiza Cristina Robalo Cordeiro (Cordeiro, 1991: 249), o nouveau roman é: "um romance que não encontra já a sua base de apoio na construção de um universo de personagens e intriga bem sólidas e delineadas, e em que o espaço é contexto estranho e o tempo voluntariamente confundido", indo, então, "buscar a sua grande força de sedução ao movimento da escrita, à palavra que se transforma em objecto e assume total autonomia". Deste modo, ainda de acordo com a autora citada, "o comment, a façon de dire são o

\footnotetext{
1 Nascido em Nice em 1940, de origens familiares mistas franco-mauricianas, Le Clézio, com dupla nacionalidade francesa e britânica, é um apaixonado pelas viagens e pelas culturas ameríndias. A sua vasta obra inicia-se com o sucesso do prémio Renaudot em 1963, atribuído a Le Procès-Verbal, continua com o êxito de Mondo et autres histoires (1978), de Désert (1980), com a sua eleição, em 1994, pelos leitores da revista Lire como o "maior escritor francófono vivo", culminando em 2008 com a consagração do Nobel de Literatura, em boa medida também devido ao facto de ser dos autores de língua francesa mais traduzidos a nível mundial.

${ }^{2} \mathrm{Na}$ obra de Claude Simon assiste-se a um movimento que vai da "escrita duma aventura" à "aventura duma escrita" (segundo a célebre fórmula de Jean Ricardou), onde a ficção romanesca desaparece para dar lugar a uma exploração do espaço da linguagem, como em Leçon de choses (1975).
} 
projecto do escritor para o qual nada existe anterior à escrita" (ibidem). Isto equivale a dizer que "a arte não precisa de uma justificação utilitária, ela cria o seu próprio sentido e existe para responder a uma necessidade interna - o movimento da escrita é elevado a uma condição de total superioridade e torna-se uma nova forma de comprometimento para o escritor" (ibidem).

No entanto, tal escrita apenas seduz um determinado tipo de leitor, o qual, almagémea do autor, se deleita com esses jogos de linguagem, contestatários nos anos 50 , subversivos na década seguinte, mas sofrendo já um movimento de refluxo com o ressurgimento renovado do romance tradicional nos anos 70.

Lentamente, então, as modernas tendências da narrativa francesa contemporânea têm vindo a percorrer novos caminhos, valorizando a nova sensibilidade: verifica-se o regresso do romanesco, do sentimento e da intimidade, da autobiografia, da atenção para com grandes causas - ideológicas, ecológicas, humanitárias, multiculturais, etc. -, mas é também evidente o retorno de um certo classicismo nas técnicas de escrita e o desejo de mutação face à ousadia de algumas experiências formais do nouveau roman. Citando novamente Cristina Robalo Cordeiro, verifica-se "que a produção [dos anos 80] dos escritores que, nas décadas de 50 e 60, revolucionaram o espaço romanesco e abalaram as mais profundas concepções do género, é agora marcada por preocupações de natureza bem diversa, mais pessoais e intimistas" (Cordeiro, 1991: 250). São exemplos disso Nathalie Sarraute (Enfance, 1983), Marguerite Duras (L'Amant, 1984), Philippe Sollers (Folies Françaises, 1989), Alain Robbe-Grillet (Romanesques - Le miroir qui revient, 1985, e Angélique ou l'enchantement, 1988). Ainda segundo a autora referida, são de destacar, no panorama do romance francês contemporâneo, nomes como os de Marguerite Yourcenar, Michel Tournier, Jean-Marie-Gustave Le Clézio ou Patrick Modiano (Cordeiro, 1991: 250251).

Contudo, já não se pode negar a perda da ingenuidade face ao código realistanaturalista. A chamada "era da desconfiança" marcou tanto os escritores quanto os leitores, e as inovações nas técnicas narrativas vieram para ficar. O actual regresso do imaginário encontra-se, em regra, ligado à criação de um mundo através da linguagem. Trata-se, sobretudo, de pinturas de paisagens interiores, em que importa mais o discurso do sujeito que percepciona o mundo do que a objectividade da realidade que descreve. $O$ novo romanesco desenvolve-se, então, numa escrita mais poética do que narrativa, em que se destaca o modo de ver e de usar os recursos retórico-discursivos.

Vem isto também a propósito, justamente, de Le Clézio, sobre quem a autora citada acima escrevia o seguinte em 1991: 
Jean-Marie-Gustave Le Clézio [...] inscrev[e]-se numa linha de reacção contra as modas intelectuais ou os poderes culturais que valorizam a opacidade da linguagem desviada do seu objectivo de mediação. [...] [E]m textos como Désert (1980) e Le chercheur d'or (1985), recusando as especulações formalistas, pretende conferir à sua escrita o peso de uma percepção subjectiva do mundo, alimentada pelos grandes temas clássicos da ficção: a exploração mental, a evocação do passado, a aventura, o desenraizamento. (Cordeiro, 1991: 251)

Quer isto dizer que, tendo-se estreado literariamente aos 23 anos com Le ProcèsVerbal, romance premiado que problematiza o código romanesco em sintonia com as propostas teóricas do nouveau roman herdadas da década anterior, Le Clézio enveredará mais tarde por um caminho bem diverso. Com efeito, se o jovem autor bebe nas fontes do existencialismo e do nouveau roman, explorando algumas fórmulas, embora com bastante independência, mostrar-se-á doravante não apenas um escritor prolífico (com mais de 40 títulos publicados até aos nossos dias, entre contos, novelas, romances, ensaios), mas, acima de tudo, revela-se como sujeito de uma escrita em constante mutação, buscando novos objectos de observação e a inovação formal.

Toda a obra de Le Clézio reflecte sobre a situação do ser humano no universo. Trata-se de uma interrogação filosófica sobre a natureza original, a matéria, o sentido da existência humana num mundo moderno, industrial e tecnológico, em clara ruptura com os elementos primordiais da vida.

Num primeiro momento, as suas obras - Le Procès-Verbal, La Fièvre (1965), Le Déluge (1966), La Guerre (1970), Les Géants (1973), Voyages de l'autre côté (1975) descrevem um universo em crise, subordinado à perturbadora e angustiante loucura que se vive nas grandes cidades do mundo moderno ocidental, invadidas pelas máquinas e pelo excesso populacional, surgindo a vida urbana como um inferno corruptor dos seres humanos. Para Le Clézio, a única salvação encontra-se no repúdio deste tipo de sociedade, na errância e/ou na arte da escrita, aspectos que doravante irão estar presentes em todas os seus textos. Desta forma, pode-se considerar que, desde este período, as suas obras revelam igualmente preocupações ecologistas, nomeadamente Terra amata (1967), Le Livre des fuites (1969), La Guerre ou Les Géants.

Servindo-se, justamente, da escrita como meio de autoconhecimento e de tentativa de compreensão dos outros e do universo, Le Clézio viaja - literal e metaforicamente falando - por várias culturas, transmutando-se de uma estética próxima do nouveau roman para uma outra que, a pouco e pouco, abraça um classicismo renovado, baseado tanto no lirismo como na aventura e na exploração dos grandes espaços, recuperando o romanesco, 
o maravilhoso, o mitológico, o histórico, etc., mas transfigurando os códigos narrativos do passado.

Se tal mudança é clara a partir de 1980, data da publicação do best-seller Désert e do reconhecimento da sua obra por parte da Academia francesa, com a atribuição do grande prémio Paul-Morand, ela pode, contudo, ser já detectada antes. Com efeito, a revelação do mundo ameríndio, desde 1966, constituir-se-á como um momento decisivo nessa viragem, nesse despertar para a celebração da natureza, em busca da harmonia entre o ser humano, o tempo e o universo ${ }^{3}$ (cf., entre outras, Mondo et autres histoires, 1978, obra da nostalgia da inocência infantil anterior à sociedade industrializada). Tal busca corresponde à do paraíso perdido da infância, símbolo da inocência, assim como da verdadeira natureza humana e liberdade. Porque é no fundo de cada um de nós que se deve, afinal, procurar o verdadeiro tesouro: não se trata de ouro, mas da beleza e da eternidade do mar e das estrelas, numa palavra, da felicidade, que só se encontra no vitalismo da natureza (cf. Le chercheur d'or, 1985, e Voyage à Rodrigues, 1986).

A obra que aqui nos ocupará, Printemps et autres saisons (1989), é composta de cinco novelas: "Printemps", a mais longa (cerca de cem páginas) e que dá o título à colectânea, iluminando-a, seguida de "Fascination", "Le temps ne passe pas", "Zinna" e "La saison des pluies". Cinco estações, portanto, construídas em torno de cinco figuras femininas, respectivamente: Libbie-Saba (marroquina-berbere), "la bohémienne aux roses" (jovem cigana), Zobéïde-Zoubida (árabe), Zinna (judia do Norte de África) e Gaby (crioula). Cinco personagens femininas, que nos falam ou de quem se fala, e que são símbolos de transformação, de errância, de renascimento para o amor e para a vida.

Nestas narrativas predominam as sensações exacerbadas, a paixão indomada, uma incontida ânsia de verdade e de liberdade. Todas elas encenam a temática da busca e decorrem num tempo cíclico, marcado pelo eterno retorno, e num universo finito. Também aqui se verifica aquilo que Michèle Gazier considera marcante em toda a obra de Le Clézio: uma tentativa de reconciliação com o mundo, através de um mergulho nas recordações e nos tempos passados como fonte de inspiração para a vida e para a imaginação. Mas, sobretudo, revela-se uma escrita da sensação concreta, da realidade primordial, uma escrita mágica, intemporal e eterna como a dos contos, poemas ou preces (Michèle Gazier, "Voyages sans retour" in Télérama, 5 mai 1999, apud Hamon \& Roger-Vasselin, 2000: 740).

Com efeito, a obra de Le Clézio, segundo Maria Dolores S. Garrido, "foi crescendo em depuração e sentido humanista, nela pulsando sentimentos resultantes da evolução humana, a que não são alheias mudanças nos sistemas políticos, sociais, culturais e

\footnotetext{
${ }^{3}$ O universo ameríndio, diz Le Clézio, "a changé toute ma vie, mes idées sur le monde et sur l'art, ma façon d'être avec les autres, de marcher, de manger, d'aimer, de dormir, et jusqu'à mes rêves" (apud Hamon \& RogerVasselin, 2000: 737).
} 
literários" (Garrido, 1999: 261). Tal como vimos atrás, também Maria Dolores S. Garrido se refere aos primeiros textos do escritor como lugares onde se encenam "problemas de violência, destruição, fuga num contexto de agressividade urbana incontrolável, anuladora do ser humano" (ibidem). Contudo, nota a mesma autora, "a partir das obras produzidas em finais dos anos setenta [...] as preocupações globalizam-se, alargam-se a mais vastas dimensões do homem, apesar da manutenção ou recrudescimento de idênticos problemas" (ibidem). E precisa que tais problemas são devidos à "proliferação das grandes cidades" e a "fragilidades que implicam a necessária instauração de mais dignas relações inter-pessoais e uma renovadora comunhão com a natureza, num processo de busca de alternativas redentoras, em detrimento do fechamento sobre si próprio perante o absurdo da existência" (Garrido, 1999: 261-262).

Então, numa obra que vai reflectindo a transformação social "e a maturidade de um escritor na sua apreensão e busca do essencial", diz ainda a autora crítica referida, "o dinamismo da viagem [...] assume-se como um possível construtor de harmonia, de equilíbrio, paralelamente à estrutura caótica do mundo" (Garrido, 1999: 262). Com efeito, trata-se, sobretudo, de uma errância que visa "uma libertação dos limites da razão"; ela é "abertura à afectividade, emoção, sensibilidade" (Garrido, 1999: 269). Esta errância corresponde a um questionamento sobre a condição humana, dado que "confirma a irreversibilidade do tempo e as actuais mudanças frequentes de configuração do espaço, apagando muitos dos traços que pareciam definir o esboço de um seguro e definitivo destino" (Garrido, 1999: 268). No entanto, convém não esquecer que "errar" se constitui como "um processo lento, longo, árduo", o qual "instaura a dúvida sobre a eficácia quanto à possibilidade de alcançar o objecto pretendido, no emaranhado do espaço, onde se entretecem fios obscuros e ambíguos, de fusão entre o real e o imaginário; o ínfimo e o infinitamente grande" (ibidem).

$\mathrm{Na}$ colectânea intitulada Printemps et autres saisons, as personagens surgem igualmente marcadas pela errância, tanto implícita como explícita, em busca da liberdade e da identidade. Estas cinco figuras femininas, oriundas de diferentes paragens extraeuropeias como se disse acima, são seres na transição da infância inocente para a idade da consciência de si e dos outros. Por exemplo, Libbie-Saba, protagonista e narradora da narrativa inaugural e mais extensa, revela a passagem da menina abandonada pela mãe adolescente ao dealbar do estádio desinibido de mulher que busca a sua emancipação e autonomia. Por seu turno, Zobeïde-Zoubida, cujas origens ela mantém secretas ${ }^{4}$, permanecerá para sempre errante e inapreensível, uma imagem apenas fixada pela foto

\footnotetext{
${ }^{4}$ Cf. "Mais j'ai pensé - diz o narrador David - que c'était peut-être comme ça dans son pays, en Syrie, au Liban, ou peut-être en Egypte, ce pays dont elle [Zob̈̈ele] ne parlait jamais, comme si elle n'était née nulle part" (Le Clézio, 1989: 155).
} 
antiga e pelas recordações do narrador David. Gaby, que acompanharemos da infância à morte, errará por entre os contrastes gritantes dos espaços geográficos, sociais e culturais exótico e francês.

No entanto, como o espaço labiríntico e caótico da cidade ${ }^{5}$ francesa se mostra, em regra, ameaçador e avassalador, a deambulação ao acaso pela urbe hostil configura a busca interior que visa reencontrar a harmonia perdida do tempo e do espaço luminosos da infância, entrevista, porém, na contemplação do mar $^{6}$ ou da colina. Errar serve, então, para reavivar as memórias, despoletando as contínuas analepses, aspecto que está bem patente em "Printemps", onde, como nota Maria Dolores S. Garrido: "emerge a alegria da descoberta da fundamental e necessária identidade feminina, embora ressalte também a tristeza do desenraizamento e condenação, presentes na confirmação da continuidade da errância, que está implícita numa designação sobrenatural ““ (Garrido, 1999: 269).

No conjunto das narrativas que compõem a colectânea Printemps et autres saisons, as diferentes figuras femininas surgem-nos como seres singulares, fascinantes, em regra relacionados com o mar e ansiando por liberdade. É uma imagem do sexo feminino como aquele que mais facilmente sente $o$ apelo da Natureza e nela procura integrar-se, funcionando como "principal agente de modificação da sua existência e exerce[ndo], explicitamente, o seu domínio", diz Maria Dolores S. Garrido (1999: 280), que acrescenta que, "para o homem, com quem se cruza e interage é obsessão, iluminando ou escurecendo o cenário, consoante está presente ou ausente" (280-281). Neste grupo de textos, a mulher revela-se detentora tanto de "uma exótica e macia sensualidade" (Garrido, 1999: 281), como "de uma maior sabedoria, provinda de uma idade de maior consciência, em confronto com um estádio de mais longa inocência relativamente à personagem masculina" (ibidem).

Contudo, todas elas se revelam sempre "exiladas, nómadas, deslocadas do seu habitat natural, vivendo sob o peso do 'souvenir ensoleillé de l'endroit édénique'" (ibidem). Efectivamente, elas estão em constante, mas circular, mobilidade, a qual foi despoletada ou pela necessidade ou "pelo desejo de fuga do espaço original que passa, posteriormente, a

\footnotetext{
5 "A cidade tem o poder de condicionar o tempo cronológico, dando-lhe uma dimensão de estatismo, de paragem de muitos dos seus actantes, fazendo despoletar o fluxo de tempo psicológico. Ergue-se como um tempo em que a felicidade se interrompe. A vida muitas vezes fica suspensa até ao desejado retorno que um tempo cíclico vai preparando. A menos que a morte ocorra antes da estação seguinte" (Garrido, 1999: 282).

'Segundo Maria Dolores Garrido, o mar é, para Le Clézio, um espaço de libertação, motivação da viagem, tesouro; espaço de separação e união, de partida e retorno, de movimento e quietude, de exaltação e apaziguamento (cf. Garrido, 1999: 277). Como refere a mesma autora, "na colectânea Printemps et autres saisons, muitas personagens estão ligadas ao mar, porque o atravessaram na ânsia de, no outro lado, encontrarem o Éden, cujas árvores e flores o betão cristalizou ou destruiu. // No conto Zinna, o primeiro encontro desta personagem com Tomi ocorre nas proximidades do mar, mesclado de um cariz iniciático. Ela parecia provir da água, como uma menina do mar: 'Zinna était si étrange. C'était comme si elle sortait de la mer'.// [...] Em Zinna o mar afigura-se como espaço de recordação, de sossego de alma, de errância interior, lugar onde repousa o olhar e o pensamento. // [...] O mar afigura-se, de facto, como um dos motivos tutelares de Le Clézio, um espaço revelado, de busca produtiva, de passagem, de apelo a novas e sucessivas errâncias, num desejo de aceder ao outro lado. Sobre a vastidão lisa ou em movimento, sobressai o azul que confirma a atracção mítica pelo absoluto, ao qual o mar também dá acesso" (Garrido, 1999: 278).

É a vontade de Deus, segundo a mãe da protagonista (cf. Le Clézio, 1999: 116).
} 
exercer a atracção do retorno e que transforma o lugar sem referência num ailleurs, enquanto o tempo vai ditando novas errâncias" (ibidem): em todas estas personagens femininas se verifica o mesmo percurso: partida triunfal, ruptura, fracasso e regresso (ibidem). Assim, tal manifestação constante do desejo do eterno retorno transporta-nos, como afirma ainda Maria Dolores S. Garrido, "a um tempo mítico anulador da oposição morte/vida, aberto à eternidade. O desejo de regresso à sua ilha implica a crença num espaço-refúgio, na existência de um centro espiritual primordial" (ibidem).

Nestas narrativas as personagens surgem, então, como seres errantes, em busca de si próprias e do sentido para a vida, o que quer dizer que, ao errarem, elas viajam, vagueiam, deambulam por espaços diferenciados, mas também que cometem erros - os erros próprios de quem está a aprender a viver, estádio que, em bom rigor, se prolonga até ao momento da morte (cf. Zinna e Gaby). Transformam-se, assim, em figuras exemplares, modelos de diversas formas de libertação, de apagamento de fronteiras geográficas, culturais, sociais.

Contudo, tanto em "Printemps", narrativa autodiegética da protagonista Libbie-Saba, como nas restantes quatro, em que os focos e as vozes narrativos são masculinos, dandonos a ver ou a imaginar os retratos fragmentários das figuras femininas, estamos perante histórias breves, aureoladas de mistério e que, evanescentes, convidam à empatia, ao sonho, à evasão do leitor, mas também à sua transformação interior.

Para tal contribui sobremaneira o facto de elas serem contadas de um modo cristalino e luminoso, num estilo fortemente poético, ao ater-se à evocação subtil dos sentimentos mais íntimos e complexos e à depuração da linguagem. Podemos dizer que a escrita poética de Le Clézio resulta da busca da simplicidade da expressão, que contrasta com os complexos labirintos da memória por onde as personagens se movem, arrastando consigo o leitor, que se vê obrigado a encontrar o fio de Ariadne.

Em "Printemps", justamente, o leitor tem de reconstruir o puzzle dos acontecimentos, porque a narrativa não é linear. Trata-se de uma narrativa autodiegética de uma adolescente marroquina (de origem berbere), construída à maneira de um diário íntimo algo caótico, onde os pensamentos flúem ao sabor das sensações e das memórias que estas despoletam, tanto as positivas, ligadas a uma infância feliz num espaço exótico, como as negativas, que marcam o aqui e agora da escrita numa cidade do sul de França, local sentido pela jovem como um exílio forçado.

Através da palavra, Libbie-Saba Zayane procura conhecer-se a si própria e dar sentido à vida, pois sente-se desenraizada, incompreendida, enganada pelos adultos no domínio dos afectos. Em primeiro lugar, descobre que a mãe biológica, quando adolescente, a vendera, tal como uma escrava (Le Clézio, 1989: 20), ao casal que ela vê como pais carinhosos, mas que the mentiram toda a vida sobre a transacção, revelação que a faz 
adoecer gravemente. Quando recupera, sai de casa, desejando viver em total liberdade. Porém, a sua nova amiga Morgane (sugestivo nome da tradição arturiana, qual fadamadrinha perversa) trai a sua confiança ao tentar seduzi-la (100-106), tal como fizera o seu professor "Green", que a desflorara (87-91). Sem família, sem amigos e/ou amantes, a jovem encontra-se num profundo desespero, errando para sobreviver ao fracasso e para se reencontrar.

Assim, a solidão do presente e a falta de esperança no futuro marcam a narrativa, fazendo contrastar a harmonia do paraíso perdido de uma infância dourada com a dureza e a fealdade do aqui e agora. O estado de crise da adolescência é analisado de forma fragmentada e incoerente na aparência, pela própria personagem em sofrimento que, través da escrita tão labiríntica como as suas memórias, dá conta dos seus sentimentos complexos e profundos. Surge, então, como uma personagem em busca da sua própria identidade, das suas raízes e do sentido da sua existência após a ruptura com o idílio infantil ${ }^{8}$, o qual deseja fazer reviver pela magia da palavra:

La nuit, j'écoute les coups de mon cœur. J'attends, les yeux ouverts, je ne sais pas ce que j'attends. C'est comme si c'était caché, que ça allait apparaître. Autrefois, tout était simple et facile. J'étais Saba, c'était le nom que j'avais reçu à ma naissance, et ma famille c'était Monsieur et Madame Herschel. J'allais à l'école de Mehdia, il y avait des enfants des soldats américains, des Français, des Arabes. On parlait dans n'importe quelle langue. Ça ne m'intéressait pas beaucoup. Ce que j'aimais, c'était cette grande maison avec des briques autour des portes et des fenêtres, au milieu des champs de sorgho et des vignes, et le grand jardin planté de tomates, de haricots, d'artichauts, et juste derrière commençaient les dunes piquées de chardons, et le bruit de la mer.

C'est cela que j'attends, chaque nuit, ici, dans l'appartement de la Loge. Que tout revienne en arrière, vers ces années-là, le ciel bleu si clair, les champs, la tache sombre de la forêt de chênes-lièges, la ligne des montagnes. [...] (Le Clézio, 1989: 67)

A percepção do mundo, dos outros, de si própria e da sua história pessoal modificaram-se depois da doença grave que a afectou e quase a matou. Em termos simbólicos, podemos considerá-la uma prova(ção) semelhante a um rito de passagem, metáfora de um renascimento, agora para a vida adulta. Também não será por acaso que essa doença ocorre na viragem do Inverno (época de trevas no húmido e sombrio

\footnotetext{
${ }^{8}$ Cf. o aqui e agora do apartamento da sua mãe no $6^{\circ}$ andar da rua da Loge, "sous les toits, sans vue et presque sans soleil [...]; cette maison lépreuse" (Le Clézio, 1989: 13-16) e a visão dourada da infância na quinta de Nightingale com os Herschel, perdida para sempre, ou "la méchanceté de l'enfance interrompue" (76); em consequência, a duplicidade e a transformação interior: "je suis deux" (47); "''autre côté du monde, [...] l'autre versant de ma vie", "peut-être que je suis vraiment devenue quelqu'un d'autre" (124).
} 
apartamento da Loge) para a Primavera (iluminada pela luz do Sol), marcando o renovar do ciclo natural, onde o ser humano se integra como todos os outros elementos da Natureza: "Alors, quand j'étais sortie de ma maladie, j'avais vu cette belle lumière au-dehors, parce que maintenant le soleil se couchait tout à fait à l'ouest, loin derrière la ligne violette des collines, et j'avais eu envie de disparaître [...]. // C'était la première fois que je voulais cela très fort" (Le Clézio, 1989: 19).

Assim que tem de novo forças, a jovem sai de casa, em total ruptura com o seu passado, para percorrer o espaço labiríntico da cidade, mas, sobretudo, para chegar ao mar. Contemplando a vastidão líquida, ela deambula em pensamentos, imaginando as transformações do mundo em seu redor se desaparecesse por alguns anos. Então, no seu regresso, já ninguém a reconheceria e ela poderia reinventar-se livremente (cf. 23-24). Neste período de renascimento, Libbie-Saba, erra efectivamente em busca de si própria, pretendendo abandonar todos aqueles que ela sente que a traíram. Contudo, no final, sentindo o peso avassalador do fracasso da sua tentativa de romper com o passado, ela regressa a casa e reconcilia-se com a mãe, parecendo agora aceitar-se, na sua verdadeira identidade (cf. 126). Este retorno ao seio materno, esta religação às suas raízes permitir-lheão, talvez - a narrativa deixa essa hipótese em aberto -, olhar para a vida futura com mais esperança de reencontrar a felicidade perdida, não a da inocência infantil, mas a da consciência da entrada na idade adulta; como se tudo - revelação da verdade, doença, errância, experiências eróticas e afectivas - tivesse consistido numa prova iniciática, que, superada, a liga de novo às suas origens, cumprindo um ciclo.

"Fascination" é uma breve narrativa de quinze páginas, construída sob o signo do desejo e orientada pelo olhar fascinado do narrador masculino, que, em adulto, evoca as suas memórias de um tempo perdido, na passagem da infância à adolescência (treze anos). O incipit coloca uma série de questões onde se manifesta uma inquietante estranheza (própria do fantástico, segundo Freud) face à entrada, no restaurante onde se encontra despreocupadamente a jantar, de duas figuras femininas peculiares, uma jovem acompanhada de uma mulher idosa:

Elle est apparue de nouveau, cette nuit. Pourquoi de nouveau? Est-ce que je l'avais vraiment déjà vue, ailleurs, dans un autre temps? Est-ce que je l'avais seulement rencontrée? Pourquoi ai-je eu alors cette impression, ce coup au cœur, quand elle est entrée, cette nuit, dans cette salle immense, accompagnée de cette vieille au regard de sorcière, toutes deux vêtues de noir comme les tziganes, et qu'elle a commencé à traverser le restaurant, sans souci pour l'émoi qu'elle provoquait, son beau visage dédaigneux éclairé et capté par les jeux de lumière et d'ombre venus des plafonniers? Pourquoi alors ai-je senti sa présence, avant même de l'avoir vue, de les voir toutes deux, quand elles avaient poussé la porte vitrée, venues du mystère de la nuit dans 
cette ville terrible, comme réfugiées dans cette salle immense au bruit de volière? Oui, j'ai senti cela en moi, comme un regard étranger, comme un mouvement de l'air sur ma peau, un danger presque, et elles entraient dans cette salle, immense et étrangère [...]. Mais pourquoi mon cœur battait-il plus vite, plus fort, comme si cet instant avait une importance extrême, et rien de ce que je vivais, rien de ce que j'avais vécu n'étaient au hasard? [...]

De quoi avais-je peur? En quoi les deux bohémiennes [...] pouvaient-elles me menacer? Pourtant, c'était ainsi: je ressentais cette scène comme si elle n'avait de sens que pour moi, parce que j'y étais. Comme si les deux femmes en noir n'étaient pas entrées dans la salle de ce restaurant pour vendre leurs fleurs, mais pour me chercher. (Le Clézio, 1989: 129-131)

A aparição fulgurante, no presente da narrativa feita pelo homem adulto, de uma "jeune bohémienne" de misteriosa e fascinante beleza, que o olha de forma intensa e profunda (cf. 129-133), fá-lo passar sucessivamente da apreensão a "un incompréhensible et stupide bonheur" (133), que, estranhamente, transforma os últimos dezoito anos da sua vida em insignificantes ilusões (133-134):

\begin{abstract}
Maintenant le pont du regard de la bohémienne m'unissait à l'autre versant de moimême, et abolissait l'irrégulière frontière du temps. J'étais moi-même, enfin, de nouveau moi-même. Rien n'avait changé en moi, j'étais cet enfant de treize ans qui rentrait chez lui après la classe, montant le boulevard en portant ses livres et ses cahiers entourés d'un élastique. [...]

C'est son regard que j'ai reconnu. C'est lui qui me ramène longtemps en arrière, à cette maison blanche au bord du boulevard. Je reviens de l'école, l'hiver [...]. (Le Clézio, 1989: 134-135)
\end{abstract}

Esta fantástica experiência de súbito transporte no tempo e no espaço das memórias do narrador-personagem (digna da proustiana colherzinha de chá com migalhinhas de madalena) coloca, analepticamente, em cena uma rapariguinha cigana detentora de um olhar "brûlant, fiévreux dans son visage pâle" (137) ${ }^{9}$. Ela tenta conquistar o rapaz, mas este furta-se com medo de ser seduzido, raptado, "d'être dérobé, de devenir un autre, de changer [s]on destin" (141). No interior do jovem adolescente, debatem-se a atracção e a razão, ganhando a última. Contudo, esta situação afectiva mal resolvida do passado parece ter voltado, dezoito anos depois, para perturbar o homem adulto no presente da escrita, através do mesmo fascínio exercido pelo olhar da jovem figura feminina que entrara no restaurante.

\footnotetext{
${ }^{9}$ Cf. "Je me souviens maintenant, du fond de cette salle immense, vide, effrayante, sous le regard de cette jeune femme inconnue qui efface le monde, je me souviens de chacun de ces instants que je croyais oubliés. Un aprèsmidi avant l'été [...]" (Le Clézio, 1989: 140).
} 
No caso de se tratar realmente da mesma pessoa, o final da narrativa deixa em aberto a hipótese de o narrador não mais vir a libertar-se desta fascinação, agora alimentada pelo suposto olhar de desprezo lançado pela jovem vendedora de flores:

[...]. Je n'ai pas revu la petite fille en noir, ni sa grand-mère au regard méchant. Le temps les a englouties, et les mouvements de ma vie les ont effacées de ma mémoire.

Jusqu'à cette nuit, où elles ont apparu à nouveau, brièvement. Alors la jeune femme s'est arrêtée devant moi, elle m'a regardé. Puis d'un seul coup, elle a détourné son regard, avec une expression cruelle de dédain et de colère. La grande salle vide résonnait à nouveau des brouhahas des noceurs. La musique jouait un air faussement enjoué, une rumba qui creusait un vertige dans mon corps. Entre les tables, la vieille femme au panier de roses et la jeune femme vêtue de noir glissaient très vite, disparaissaient. Un instant encore, comme dans un rêve, j'ai vu leurs silhouettes devant la porte, puis elles se sont engouffrées dans la nuit. (Le Clézio, 1989: 143)

Em "Le temps ne passe pas", breve narrativa de quinze páginas, aborda-se a problemática da inexorável passagem do tempo, mas à qual a adolescência não dá a devida importância, pois vê-se com a vida toda pela frente, com todo o tempo do mundo. Por outro lado, tal como em "Fascination", as experiências desta fase da vida mostram-se eternas e ficam gravadas para sempre na memória, constituindo a fonte das boas e más recordações, como o narrador-personagem David descobre relativamente à bela e misteriosa ${ }^{10}$ ZobeïdeZoubida. Nesse Verão evocado pela memória, tinha ele então dezasseis anos e ela apenas mais dois. Contudo, ele sentia-se como uma criança perto da jovem de misteriosas origens árabes e deixava-se conduzir por ela (154):

Elle me regardait avec moquerie. Je ne savais pas ce que je voulais d'elle. Simplement regarder son visage, ses yeux sombres, toucher sa peau, tenir son corps dans ses vêtements blancs, sentir son odeur. [...] Un après-midi, nous étions allongés sur les aiguilles de pin, dans la colline, nous nous sommes embrassés pour la première fois. [...] En bas, nous nous séparions brutalement, sans rien dire, sans nous fixer de rendez-vous, comme si nous ne devions jamais nous revoir. C'était son jeu, elle ne voulait rien qui la retienne. J'avais peur de la perdre.

\footnotetext{
${ }^{10}$ Cf. "Tout en elle était mystérieux. [...]. Sur cette photo, je la trouve très belle, très étrange. [...]. Ce que je vois, c'est son visage surtout, le visage qu'elle a à cette âge, sur la photo, l'arc parfait de ses sourcils comme dessinés au charbon, ses yeux sombres et profonds, brillants, et cette chevelure noire où s'accroche la lumière. Quand je l'ai connue, elle portait encore les cheveux en une seule natte épaisse qui descendait jusqu'à ses reins. Jamais elle ne se montrait avec les cheveux défaits, et j'imaginais cette chevelure noire tombant en pluie sur ses épaules et dans son dos. [...]. Je voyais sa peau brune [...]" (Le Clézio, 1989: 148-153).
} 
C'est à cette époque qu'elle m'a donné sa photographie. [...] Ses yeux brillaient étrangement, avec fièvre. Je comprends maintenant, quand je regarde la photo, c'était elle qu'elle donnait. Comme si elle n'avait jamais eu d'autre vie, d'autre visage. Alors c'est tout ce qui me reste d'elle. (Le Clézio, 1989: 154-157)

Na verdade, Zoubida desaparece sem deixar rasto, destroçando o coração de David. Este ficará até à idade adulta fascinado e apaixonado por ela, mas também arrependido da sua incapacidade de adolescente para então haver compreendido esta enigmática figura feminina e para a ter retido junto de si. Resta-lhe apenas uma foto desbotada e as memórias sensitivas dos ardores daquele Verão, irremediavelmente perdido. Contudo, a expressão "le temps ne passe pas”, que dá o título à narrativa, acentua a busca incessante do narrador, prisioneiro de uma recordação obsidiante, que o leva a regressar ciclicamente àquele lugar na esperança de, ao reencontrar o fantasma de um amor perdido, reviver igualmente a felicidade livre e despreocupada da juventude. Trata-se de uma espécie de movimento de eterno retorno, que a escrita cristaliza:

Maintenant, chaque été qui approche est une zone vide, presque fatale. Le temps ne passe pas. Je suis toujours dans les rues, à suivre l'ombre de Zobïele, pour essayer de découvrir son secret, jusqu'à cet immeuble au nom si ridicule et triste, Happy days. Tout cela s'éloigne, et pourtant, cela fait encore battre mon cœur. Je n'ai pas su la retenir, deviner ce qui se passait, comprendre les dangers qui la guettaient, qui la chassaient. J'avais le temps, rien n'était important. Je n'ai gardé d'elle que cette photographie d'une école où je n'ai même pas été. Le souvenir de ce temps où chaque jour était la même journée, une seule journée de l'existence, longue, brûlante, où j'avais appris tout ce qu'on peut espérer de la vie, l'amour, la liberté, l'odeur de la peau, le goût des lèvres, le regard sombre, le désir qui fait trembler comme la peur. (Le Clézio, 1989: 161; itálicos meus)

Zinna é a figura feminina que se segue, emprestando o seu nome à quarta narrativa. No início, ela é apresentada como uma judia magra, pobre, coberta por um velho casaco cinzento. Contudo, trata-se de uma bela jovem, de olhos verdes e farta cabeleira frisada, quase vermelha, mais precisamente, "couleur de cuivre" (Le Clézio, 1989: 165-167).

Apesar do seu aspecto frágil, ela é detentora de uma prodigiosa voz de cantora de ópera, que a todos cativa e seduz, tanto o seu fiel amigo Tomi-Gazelle ${ }^{11}$ como o seu professor de música (o violoncelista cinquentão e casado, Jean André Bassi), explicitamente responsável pelo foco e pela voz narrativos em dois de um total de seis capítulos: "C'était

\footnotetext{
${ }^{11}$ Cf. o incipit: "Il s'appelait Tomi, mais Zinna l'appalait Gazelle [...]" (Le Clézio, 1989: 166). Trata-se de um jovem de catorze anos, órfão, que vive na rua e rouba para sobreviver. Apaixonado por Zinna, segue-a para todo o lado.
} 
une voix, comment dire? irréelle, celeste. J'étais attiré par sa voix comme si on me tirait en avant" (170); "sa voix surnaturelle" (171). Zinna entra na vida do casal Bassi e provoca, com o charme da sua voz, uma profunda transformação:

Rien n'était comme avant. Zinna était sans cesse présente, même si je ne la voyais qu'au moment des leçons, ou parfois, au hasard, dans les rues voisines, dans les escaliers. Je ne comprenais pas ce qui m'arrivait. C'était peut-être de l'amour, du désir, mais alors je n'y pensais même pas. Pas un instant je n'avais imaginé cela. Peut-être que c'était elle, sa jeunesse, sa beauté, ou bien le son de sa voix, qui m’avaient envoûté, qui m'avaient lié. (Le Clézio, 1989:175)

Mais tarde, Zinna desaparece, abrindo involuntariamente uma brecha na relação conjugal dos Bassi: "Maintenant, Zinna est partie. Elle n'a pas dit où elle allait. Elle ne s'est pas présentée au concours. Elle s'est effacée, simplement" (Le Clézio, 1989: 177). Aquando de uma violenta crise de asma, Juliette Bassi confronta o marido em relação a Zinna ("Tu l'aimes", 177); então, "malgré [s]es promesses, [il a] laissé les infirmiers l'emmner à l'hôpital" (178).

O desaparecimento súbito de Zinna indicia um espírito ansiando por liberdade e em busca do seu próprio caminho. Obrigada a exilar-se em França ainda em criança, o seu bairro natal constitui para ela uma espécie de paraíso perdido, que ela se compraz a evocar, envolvendo Tomi-Gazelle nessa nostalgia através do encantamento da sua voz e da sua narrativa, lembrando Xerazade: “Tu sais, Gazelle, quand j'étais toute petite, il n’y avait pas de plus beau quartier que le Mellah. / Zinna commençait toujours ainsi. [...] / Zinna parlait lentement, comme si elle cherchait à se souvenir. Tout était si loin, perdu de l'autre côté de la mer" (Le Clézio, 1989: 179-180). Através da repetição da sua narrativa, Zinna revive a felicidade de outrora, que se opõe ao infortúnio presente: "Zinna parlait de sa ville, les ruelles qui descendent, les escaliers, les portes secrètes, les passages, et en bas, le grand fleuve avec la vague de la marée qui pousse les branches mortes et chasse les mouettes. I 'Tu sais, Gazelle, le Mellah c'était le monde pour moi. [...]'” (181). Tomi deixa-se levar pela narrativa de Zinna, imaginando-se a viver a mesma experiência (184). Por esta altura, Zinna tinha já desaparecido de casa dos Bassi, muito provavelmente por ter conhecido o rico Maître Orsoni, de quem se tornara amante, na eventual esperança de poder realizar o seu sonho - regressar ao seu paraíso perdido.

De facto, Orsoni, um poderoso homem de negócios sem escrúpulos, "avait propulsé Zinna, comme d'autres avant elle" (189). Durante cinco anos, ele explora o talento da jovem, seduzindo-a com "l'argent, les relations, le monde du spectacle" (189), as viagens no seu luxuoso iate (196-197). Contudo, tal como com as outras, tratava-se tão-só de uma perigosa 
armadilha, onde era sugado todo o talento das jovens e efémeras divas, iniciadas numa vida de drogas e futilidade. Em compensação, ao turbilhão da fama sucedia-se invariavelmente a queda, a degradação, o vazio existencial. Assim, a princípio, Zinna

ne pensait pas aux femmes qu'Orsoni avait façonnées avant elle, celles à qui il avait tout appris, jusqu'à leur propre nom, et qui ensuite étaient tombées: retournées à leurs machines à écrire, à leurs séances de pose, à leurs expédients, ou bien plus bas encore, devenues entraîneuses, strip-teaseuses, taxi-girls. Et maintenant, on parlait aussi, à mots couverts, de celles qui étaient tombées vraiment. Après ces mois de fête, la rupture avait été insupportable, elles n'avaient pas supporté le vide. On parlait d'elles comme d'absentes, comme de mortes. (Le Clézio, 1989: 189-190)

Após cinco anos de vida de celebridade, Zinna sofre o mesmo destino. Já antes do final da sua carreira artística, os sinais de esgotamento são visíveis: "C'était un tourbillon qui l'emportait à travers le monde, dans la nuit, de lumière en lumière, brûlant son visage, ses yeux, sa voix" (191). Abandonada por Orsoni, será Tomi a tomar conta dela nesta nova fase negativa da sua vida: "Pâle, maigre, dans sa robe noire. Zinna ne bougeait plus de l'appartement [...]. Quand Tomi est revenu là, après toutes ces années, il a eu peur, parce que c'était devenu si vide. Rien n'avait changé vraiment, mais c'était l'abandon, la solitude" (193). A transformação da atmosfera nesse local deve-se ao estado de espírito de Zinna, completamente perdida nas suas ilusões (196-197), embrenhada na teia da droga (194196), fraca, só, vazia, caminhando para o abismo existencial, a loucura, o suicídio (197-198): "Elle était si faible qu'elle ne pouvait plus marcher, plus manger, plus dormir. Le vide était en train de la dévorer" (201). O seu maior desejo é regressar "chez elle" - ao Mellah (201). No limiar da vida, e apesar dos cuidados extremosos de Tomi, Zinna é hospitalizada (198). Aí, Tomi é o único a interessar-se por ela. Depois do seu trabalho nocturno, durante o dia "il restait avec Zinna, il la regardait, il l'écoutait respirer. II tiendrait sa main longue et fine, pour sentir sa chaleur. II n'y aurait plus d'hôtels à Amsterdam, ni de bateaux, ni d'îles en Grèce. II ne laisserait plus personne détruire Zinna, sa voix, son regard" (200-201).

Recordando-se do anterior pedido de Zinna ("Emmène-moi, Gazelle, je voudrais tellement retourner chez moi, être enfin chez moi”, p. 201), Tomi decide que, um dia, a tirará do hospital, como se fossem apenas dar um passeio, e a levará para Vaujours, em substituição do amado Mellah:

Maintenant, Tomi savait bien ce qu'il ferait. Un jour, ils marcheraient ensemble hors de l'hôpital, comme s'ils allaient au bout de la rue, juste faire un petit tour avant la nuit, et revenir à l'heure du repas. Au bout de la rue, il y aurait encore une rue, encore une autre. II y aurait des routes à travers la campagne, des champs, des herbes et des 
coquelicots. Ils continueraient à marcher, sans se retourner. La nuit serait magnifique, avec des pluies d'étoiles. Comme ils ne sauraient pas où aller, Tomi conduirait Zinna jusqu'à Vaujours. [...]. Ensemble, ils ne se perdraient jamais. A nouveau, il se serrerait contre elle, il écouterait sa voix dans sa poitrine, pendant qu'elle parlerait encore de sa ville lointaine, aux ruelles étroites, aux maisons très blanches avec leurs portes bleues, et même de la fenêtre au balcon arrondi où la vieille Rahel ne viendrait jamais voir la mer. (Le Clézio, 1989: 201-201)

Estas palavras, que concluem o texto, acentuam a esperança da felicidade a dois, desejada aqui pela personagem masculina, Tomi. Como vimos, ele constitui a única possibilidade de salvação de Zinna, a jovem exilada pobre e nostálgica do paraíso perdido da sua infância, que a todos encanta com o talento da sua voz. Devido a isso, chega a conhecer uma breve vida de diva recheada de sucesso e dinheiro, mas também de drogas. Assim, tudo nela se vai degradando, caminhando para o abismo, depois de abandonada pelo agiota que a havia iludido e explorado. À beira da morte, apenas the resta o amor de Tomi, que tentará proporcionar-Ihe uma outra existência, livre e feliz, à semelhança do tempo despreocupado vivido no Mellah, acentuando, deste modo, o desejo de regresso a uma situação semelhante a um passado idílico.

Por último, surge a figura de Gaby Kervern, a protagonista de "La saison des pluies", no início da narrativa uma bela crioula de dezoito anos, grande, de olhos azuis, pele mate e cabelos pretos, cuja vida tumultuosa acompanharemos até à sua morte. De novo, esta história aborda as temáticas da busca interior, do exílio e da ânsia de liberdade ${ }^{12}$, que, no entanto, é destruída pela civilização ocidental.

Neste caso, porém, os dados parecem invertidos relativamente às histórias anteriores. Assim, após a morte do pai, a jovem parte voluntariamente para França, desejando aí encontrar a felicidade que parece escapar-Ihe na sua exótica ilha natal. Igualmente órfã de mãe, desde o seu nascimento, Gaby é apresentada pelo narrador de $1^{\text {a }}$ pessoa como ardente e ambiciosa (Le Clézio, 1989: 208). Mais adiante reforçam-se tais características: "Gaby jugeait tout avec son cœur. Pour elle, le monde était clair, sans soucis" (220). Ela diz odiar a sua ilha ${ }^{13}$ e despreza o jovem cafre, Ti coco (cujo verdadeiro nome é Claude Portal), que por ela está incondicionalmente apaixonado desde os doze anos (e assim continuará pela vida fora até morrer). Em França, Gaby casa-se com Jean

\footnotetext{
${ }^{12}$ Cf. "Partir était une délivrance. Sur son visage, sur son corps, Gaby sentait une lumière nouvelle, violente, pareille à son désir de vivre. [...]" (Le Clézio, 1989: 205).

${ }^{13} \mathrm{Cf}$. "A la mort de son père, il ne lui restait rien. Sa mère était morte à sa naissance. Sa tante Emma, qui l'avait recueillie à Curepipe, s'était facilement laissé convaincre que Gaby devait partir pour l'Europe. II n'y avait pas de place pour Gaby dans cette île. Elle détestait tout ce qui lui rappelait son enfance, la pauvreté, la solitude, la maladie. Elle détestait la chaleur lourde des lagons, la végétation qui envahissait les jardins, l'ondoiement lent des Indiennes en sari. Ce qu'elle haïssait par-dessus tout, c'étaient les fièvres et les cyclones. [...]" (Le Clézio, 1989: 209).
} 
Prat, um jovem de famílias ricas, com quem parece ter encontrado aquilo por que tinha ansiado, desfrutando de uma vida de plena liberdade, luxo, aventura e felicidade conjugal, apesar da rejeição de que é alvo por parte da família do marido (211-216).

Contudo, as circunstâncias da Segunda Guerra Mundial vêm perturbar a felicidade de Gaby, reconduzindo-a a uma situação disfórica, agora no espaço europeu, após o idílio amoroso vivido com Jean. O casal instalara-se junto ao Mediterrâneo francês em 1938, na sequência da necessária convalescença de Gaby, afectada por uma estranha inquietação que lhe enfraquece o corpo e o espírito (217-219). As causas de tal estado ansioso não são claras: elas evocam no seu espírito, por um lado, as memórias angustiantes das várias épocas das chuvas da sua infância, mas agora, que está grávida, podem muito bem ser uma espécie de premonição relativa ao avanço da situação da guerra no espaço francês. Na verdade, o estado de gravidez funciona aqui como um momento de pausa do tempo, a espera e a angústia operam essa transformação: "C'était pour cela que le temps n'existait plus, à cause de la vie qui se formait, qui rayonnait" (222).

$\mathrm{Na}$ Primavera seguinte, o marido parte para a guerra, no Norte. E "une semaine et demie après", "le bébé est venu au monde": "c'était un garçon. II arriva facilement dans un monde en déroute" (223). À felicidade do nascimento de Ini sucede-se, triste ironia do destino, um cortejo de acontecimentos terríveis e, consequentemente, longos tempos muito difíceis para Gaby:

Les mois, les années passèrent, éloignant le bonheur de façon irrémédiable. Il y eut l'armistice, l'occupation italienne. II y eut les gens défilant dans les rues de Nice pour réclamer l'expulsion des Juifs. II y eut les Italiens dans les villes des collines, la Gestapo allemande dans l'hôtel de l'Ermitage. Il y eut les cartes de rationnement, le lait mouillé, le pain noir, la viande avariée. Ini tomba malade, son joli visage devint pâle, sa peau gercée et ridée comme celle d'un vieillard. (Le Clézio, 1989: 223)

Com todo este sofrimento e uma fome atroz, Gaby transforma-se e, então, ela, "jadis si rieuse et insouciante, était devenue sombre, anxieuse. La nuit, elle ne pouvait pas dormir. [...]“ (223). Esta permanente e avassaladora inquietação agrava de dia para dia a sua dor, porque, para além do mais, ela continua numa ignorância total acerca do paradeiro de Jean, ou sequer se ele está vivo ou morto. Agora é esta a sua nova demanda, pois, ao contrário de muitos outros homens, ele ainda não regressou e, pior, nunca enviara notícias, nem para a mulher nem para a família, parecendo estar desaparecido sem ter deixado qualquer espécie de rasto: "Jean était parti à la guerre, il avait été dévoré, il avait disparu, il ne restait plus rien de lui. // Gaby essaya de se renseigner auprès des gens qui étaient revenus du front, elle demanda aux prêtres. Personne ne savait rien. Personne n'avait vu Jean. [...]“ 
(224). Este aspecto é ainda desencadeador das grandes dificuldades económicas por que passam doravante ela e o filho, pois não têm direito sequer a uma pensão por morte de Jean, e a família deste continua a desprezá-los. Enquanto aguarda notícias do marido, Gaby vê ainda a casa ser requisitada pelo exército ocupante e tem de mudar-se, o que contribui para o acentuar do seu estado deprimido e angustiado (225-226).

Com o passar do tempo, a infelicidade vai aumentando num crescendo: estranhamente Ini aos dez anos ainda não fala (226), a queda da família na miséria agravase (228), a saúde de Gaby arruína-se - primeiro sobrevém uma cegueira progressiva (229), depois fica gravemente doente com uma meningite cerebrospinal (230-232). É salva pela fome de Ini, que vai finalmente bater à porta da vizinha quando já nada há para comer em casa e fala pela primeira vez, pronunciando apenas uma palavra, mas cheia de simbolismo miraculoso: "Lu-mière" (232-233). Gaby é, então, enviada para o hospital, atravessa uma longa e difícil convalescença, salva-se, mas fica cega (232), ou seja, o seu regresso à luz da vida é pago com a dos olhos.

Contudo, esta salvação quase milagrosa dá início a uma lenta recuperação na sua vida. Também milagrosamente recebe finalmente a primeira pensão do marido ("grâce à l'argent de la pension arrivé miraculeusement", 232). Depois, ela passa a chegar com regularidade (233). Porém, na verdade, como Ini descobre no final - e é também miraculosamente que ele recupera todas as capacidades intelectuais e físicas $(233$; 241249) -, esse dinheiro era enviado por Ti coco, que, tendo enriquecido e continuando a amar Gaby em silêncio, assim procurava cuidar dela e do filho (248-249). Ou seja, sem o saber, ou não querendo prestar-Ihe a devida atenção, Gaby teve sempre neste amigo de infância o seu verdadeiro escudo protector.

Depois do rescaldo do sofrimento e da doença, tendo entrevisto o limiar da morte, Gaby, aos cinquenta e seis anos, modificou o seu temperamento, encontrando-se, agora, serenada: "maintenant, la paix est en elle, la souffrance a poli son visage comme une eau" (234). Curiosamente - ou não, tratando-se de Le Clézio - "le désir est entré en elle de retourner là-bas, chez elle, dans son île, à Vacoas. C'est un désir très fort, continu, qu'elle ne comprend pas elle-même" (234).

Tal modificação deveu-se à sensação auditiva de um ruído estranho mas que lentamente a sua memória compara com o barulho da chuva da sua infância, à qual se junta um cheiro familiar, 'l'odeur de sa mère qu'elle n'a pas connue, mêlée secrètement à l'odeur de la terre, aux feuilles pourrissantes, à l'odeur des goyaves et des mangues, à l'odeur âcre de la papaye ouverte sur la table de la cuisine, au parfum enivrant du galant-de-nuit" (235). Como Proust nos ensinou, as memórias sensitivas do olfacto e do paladar são mais poderosas e permanecem por mais tempo escondidas à espera de serem reavivadas. A estas evocações do passado junta-se a imagem fantasmática de Ananta. Assim, à beira da 
morte, o cérebro de Gaby transporta-a involuntariamente para recordações da sua terra natal que ultrapassam a sua aversão à estação das chuvas, levando-a, inexplicavelmente para ela, a desejar o retorno à ilha, que ela nunca havia sentido como paraíso perdido. $O$ motivo para esse regresso será, então, o desejo de reencontrar, "coûte que coûte", a amiga Ananta (235-236), transformando, uma vez mais, o objecto da sua busca.

O narrador acentua uma ideia de inevitabilidade do tempo cíclico e de eterno retorno através da repetição, agora no sentido inverso, do incipit, onde se fala do desejo de exílio da jovem crioula: "Est-ce qu'il pleuvait sur la rade, ce jour de février 1929, quand Gaby Kervern est montée dans la pirogue qui emmenait les passagers jusqu'au Britannia? [...]" (205). Trinta e oito anos depois, em Fevereiro de 1967, a mesma pergunta aplica-se ao desejo de regresso a casa daquela que fora apresentada como uma "jeune fille aux cheveux si noirs, aux yeux si bleus, vêtue de sa robe légère et coiffée de son incroyable chapeau de paille, [qui] s'abritait sous son ombrelle pour gagner le bord du Britannia" (236), ou seja: "Est-ce qu'il pleuvait encore, quand le dernier paquebot de l'India Steamship a mouillé dans la rade, sur la route de Bombay, et quand les canots à rame ont conduit les passagers jusqu'au môle?" (236).

Agora Gaby é acompanhada, ou melhor, conduzida devido à sua cegueira, pelo filho já homem. E é também por este motivo que ela tenta lembrar-se do lugar natal através de sons, odores, sensações tácteis. Contudo, no ar paira de novo uma "inquiétude sourde, comme avant la tempête" (237), prenúncio dos confrontos da luta pela independência. Gaby refugia-se na sua busca obstinada de Ananta, mas que é, sem que ela o saiba, igualmente infrutífera, pois a amiga já morrera há muito, facto que Ini lhe esconde (240-241).

No entanto, é $\mathrm{Ti}$ coco, agora um importante homem de negócios, que inopinadamente aparece no hotel para a ver (238-239). Mais tarde, ele começa a manifestar sinais de debilidade física, e a atitude de Gaby para com ele vai-se tornando, aos poucos, mais carinhosa, reencontrando o seu temperamento risonho, falador e descontraído da juventude. Mas Ti coco vem a morrer um ano depois, "doucement", partindo "en silence, comme il avait toujours vécu" e deixando todos os seus bens a Ini, com o usufruto de Gaby (245-246). Com o desgosto, ela adoece gravemente com uma febre que a conduz do delírio, onde encontra Ananta, à morte (246-248). Então, "sur le ciment de la tombe, dans le petit cimetière de Phœnix, Ini a fait graver leurs noms, avec seulement les dates de naissance et de décès. Maintenant, ils sont enfin couchés l'un contre l'autre, pour l'éternité" (249), cumprindo o destino sonhado por Ti coco e nunca verdadeiramente assumido, embora sentido, por Gaby, finalmente chez elle.

Como conclusão deste breve estudo das figurações do feminino no conjunto das narrativas que compõem a obra Printemps et autres saisons, é de salientar a enorme força interior e o poder de sedução destas cinco mulheres: Libbie-Saba, a jovem cigana 
vendedora de flores, Zobéïde-Zoubida, Zinna e Gaby. Trata-se, na verdade, de "cinq femmes vues ou entrevues, rêvées, pour tenter de dire la fragilité, l'étrangeté et la recherche de l'amour, la recherche de soi-même, l'errance et l'appartenance, la mémoire ou l'oubli, le temps qui ne passe pas et les lieux anciens qui s'enfuient" (cf. contra-capa da edição Gallimard). Ou seja, estas figuras femininas, que nos falam ou de quem se fala, revelam-se como símbolos de transformação, de errância, de renascimento para o amor e para a vida. 


\section{Bibliografia}

BreE, Germaine (1990). Le monde fabuleux de J.-M.G. Le Clézio. Amsterdam: Rodopi.

CHUNG, Ook (2001). Le Clézio: une écriture prophétique. Paris: Imago.

CORDEIRO, Cristina Robalo (1991). "Malraux: modernidade e comprometimento" in Monteiro, Ofélia Paiva e Oliveira, Cristina [Robalo] Cordeiro, Literatura francesa moderna e contemporânea. Lisboa: Universidade Aberta, pp. 241-251.

Cortanze, Gérard de (1999). J.-M.G. Le Clézio: le nomade immobile. Paris: Éditions du Chêne.

Di Scanno, Teresa (1983). La vision du monde de Le Clézio. Paris: Nizet.

FouCAULt, Michel (1964). "Le langage de l'espace" in Critique, № 203, avr. 1964, pp. 379-380.

GARRIDO, Maria Dolores Sousa (1999). Percursos em errância: uma leitura de textos de J.M.G. Le Clézio, pp. 259-292 [disponível em 21-11-2009] $<U R L:$ http://ler.letras.up.pt/uploads/ficheiros/5925.pdf>.

HAMON, Philippe \& Roger-VASSELIN, Denis (dir. 2000). Le Robert des grands écrivains de langue française. Paris: Dictionnaires Le Robert, pp. 734-741.

KAStBERG SJöBlom, Margareta (2006). L'écriture de J.M.G. Le Clézio: des mots aux thèmes. Paris: Honoré Champion.

LE CLEZIO, Jean-Marie Gustave (1989). Printemps et autres saisons. Paris: Gallimard.

LHOSTE, Pierre (1971). Conversations avec J.-M.G. Le Clézio. Paris: Mercure de France.

LEMAITRE, Henri (dir. 1994). Dictionnaire Bordas de littérature française. Paris: Bordas.

ONIMUS, Jean (1994). Pour lire Le Clézio. Paris: PUF.

REAL, Elena \& JiMENEZ, Dolores (eds. 1992). J.-M.G. Le Clézio - Actes du Colloque International. Universitat de València, Departament de Filologia Francesa I Italiana.

SUZUKI, Masao (2007). J-MG Le Clézio: évolution spirituelle et littéraire - par-delà l'Occident moderne. Paris: L'Harmattan. 
